\title{
Constipation, CTCAE
}

National Cancer Institute

\section{Source}

National Cancer Institute. Constipation, CT CAE. NCI Thesaurus. Code C57141.

A disorder characterized by irregular and infrequent or difficult evacuation of the bowels. 